\title{
Physics Diagnostic Test: An Approach to Qualify Astronomy Students
}

\author{
Ryan Manuel D. Guido ${ }^{1 *}$ \\ Ruby-Ann B. Dela Cruz ${ }^{2}$ \\ ${ }^{1,2}$ Rizal Technological University, Department of Earth and Space Sciences, Philippines \\ *E-mail address: rmdguido@rtu.edu.ph
}

\begin{abstract}
Keywords: Physics Education, Astronomy Education, Physics Diagnostic Test, Student Qualification
\end{abstract}

\begin{abstract}
This study determines the learning outcomes measured by the physics diagnostic test, the performance of the incoming college freshman astronomy students in the physics diagnostic test, the suitability of the physics diagnostic test as entry requirement for the BS Astronomy Technology students, and the differences in the result of the physics diagnostic test. It deals with the analysis on the conceptualization that students may have difficulties pursuing the astronomy course if they have impediments in the result of their physics diagnostic test. In the past years, it casually occurs that students with low physics adaptation results to have lower to failing grades when they reach higher astronomy subjects.

This study utilized a causal-comparative research design. A purposive sampling was used to the incoming freshmen students of BS Astronomy Technology during the first semester of school year 2014-2015 who took the 25 item validated basic introductory concepts in physics diagnostic test of the department.

The findings showed that the physics diagnostic test measured and matched the prescribed learning outcomes set by the department. It also showed that most of the students have very satisfactorily understanding in physics. Therefore, it concludes that the physics diagnostic test match entry requirement for BS Astronomy Technology and that there is no significant difference in the physics diagnostic test between the BS Astronomy Technology college freshman students.
\end{abstract}

\section{INTRODUCTION}

Diagnostic test measure students' understanding of a subject area or abilities. Teachers usually administer a diagnostic test in subjects like science, mathematics and reading to provide remedial instruction and uplift students' assessment. It provides specific information that would identify the level of understanding on a certain topic or subject matter.

Diagnostic evaluation can be written to ascertain the students' level of learning within a course or a subject. It is placed to It trails to the measurement of students' apperception on a subject matter. It also measures individual differences or achievement at a certain pre-specified mastery of the subject matter that is coherent in learning.

Students' performance can be assessed through an examination to determine the parameters and extent of understanding and knowledge a student can utilize and apply to certain skills during the period of learning.

The probable strengths and weaknesses of the students can govern by the result of the students' performance in the diagnostic tests. This may lead to the assessment of the administration to perform, provide or find other means toward student learning and performance.

Physics is considered as the most problematic area within the realm of science, and it traditionally attracts fewer students than other sciences like chemistry and biology. Most of the students perceived physics as a difficult subject during high school days and becomes more problematic when they are in college, and even more challenging in graduate education. In the Philippine setting, it is more perplexing to most of the Filipino students to study physics because of the undesirable reputation long before time. With this, only students who do well in high school physics and students that are exceptionally good in mathematics, remarkably talented and gifted in science can appreciate the role of physics in their daily life. 
With such discourse in the physics education in the Philippines, students find it to have a negative attitude toward learning physics because of its computational exigency in every problem sets, moreover, if they don't like the subject more often they don't like the teacher. One of the most prevailing teaching-learning strategies and approaches for physics teachers is to make physics amusing and entertaining in the class. Physics can be applied by several teaching methods in order to transfer learning effectively and efficiently. Such effects in teaching physics may increase the ability of the students to understand and comprehend more than the usual and the ability of their learning process can be realized.

One of the most prevailing subjects in the field of engineering is physics. Its prominence in the academic and specialized range of engineering students, which makes it a supporter of more than instrumental substance for learning all throughout the engineering course. It is the basic foundation of every engineering topics and the pedagogical significance to every engineering student [12].

\section{PHYSICS EDUCATION}

With this, in investigating student difficulties, teachers should always try to find ways to establish, enlighten, and deliberately present cognitive and affective way for students to fully understand the concept of physics. There are different ways on how teachers present topics that will trigger student reasoning that will enhance the applicability of the cognitive concepts to overcome their difficulties in physics.

In the course of physics education by the Filipino students, they tend to apply convenient and rational way that seems to be appropriate in problem solving undertakings. This shows that Filipino students studying physics use different aspects of student reasoning that would make it easy for them to understand the concept of the problem and analyze based on how they understand the given situation.

In able to help students to understand better the physics concept, implementation of the use of an instructional material is imposed to elevate students ${ }^{6}$ understanding and to reinforce student cognitive skills towards the topics.

Teaching science is one of the most important parts of education. Students' reasoning comments and rated certainties in their responses were used to determine students' misconceptions [1].

Physics education researchers have scientifically established the fact that the understanding of new concepts and interpretation of incoming information is strongly influenced by the preexisting knowledge and beliefs of students, called epistemological beliefs. This can lead to a gap between what students actually learn and what the teacher expects them to learn. In a classroom, as a teacher, it is desirable that one tries to bridge this gap at least on the key concepts of a particular field which is being taught [22].

Science had been taught in Philippines' secondary schools, with little or no experimentation or practical work, a situation often attributed to very large class sizes and lack of space [16].

Student performance in physics is also affected by how it was taught. There is an autonomysupportive instructor acknowledges students' perspectives and feelings and provides students with information and opportunities for choice while maintaining external pressure (e.g., incentives or deadlines) [13]. It was found that the degree to which students perceived their instructors are autonomy supportive was positively correlated with student interest and enjoyment in learning physics and negatively correlated with student anxiety about taking physics.

The Department of Earth and Space Sciences of Rizal Technological University is under the College of Engineering and Industrial Technology. The department aims to provide quality graduates by accommodating students with at least a satisfactory background in physics and mathematics subjects. Students applying in this course have shown interest in astronomy since their childhood days and was their primary reason for doing the course. The eagerness to learn and curiosity of the outer space makes more students apply for this course, but haven't realized the possibility of encountering enormous physics and mathematics subjects that may hinder their 
success in finishing the course if they do not possess a strong background in physics and mathematics.

The conceptualization of the study is the apparent decay of students' retention of the physics subjects as pre-requisites and co-requisite subjects in astronomy. Physics is definitely relevant to the field of astronomy as it simply discusses, explain, and elucidates the basic concepts in astronomy. Most of the students ponder astronomy as a course that can easily pass through, but haven't really fully realized the complexity of the entire program.

A diagnostic test is being administered by the department to determine the aptitude of the students who wanted to pursue bachelor's degree in astronomy. Through this the department can identify the adeptness of the students towards the possible. It is believed that students who has at least satisfactorily good background in physics can sufficiently become successful in finishing the course.

This sufficient satisfactorily good background in physics is highly addressed by the physic faculty in the department. The faculty anticipated that a student with sufficient satisfactorily good background in physics can easily understand moderate to complex physics concepts. Based on the length of teaching experience of the faculty, a student without a sturdy background in physics would require much attention on the basic concepts instead of pursuing the topics prescribed by the syllabus. Teacher quality as one and most influential factor on students' achievement and many a times, academic preparation of teachers, type of certificate, professional learning and years of teaching experience are taken as indicators of teacher quality [8, 9, 11]. The applicability of a diagnostic test will help faculty identify the strengths and weaknesses of the students as based on what they have learned during their high school days.

\subsection{Diagnostic Testing in Physics}

One means of improving the application of misconceptions research is by the use of diagnostic tests which incorporate the findings of this research [24].

A diagnostic study to investigate students' understanding of two basic formulae in physics. Based on the findings of the study, we have developed a classroom activity focused on the interpretation of formulae. The activity was developed cooperatively by physics education researchers and highschool physics teachers and was tried out in the teachers' classrooms [2]. The apparent recommendation of teaching for effective learning (learning with understanding) where students take responsibility of their own meanings for concepts and phenomena [6].

The conceptualization of testing determines the analysis, which shows significant body of empirical and theoretical work has led to a widespread acknowledgment that teaching by telling has profound limitations for developing conceptual understanding [18]. It appears that many undergraduate physics students fail to build reasoning chains from fundamental principles, even if they possess the required conceptual knowledge to do so. Instead, they often rely on a variety of intuitive reasoning strategies that have been documented in the literature $[26,15]$

There is a study that presents the categories and assesses the quality of questions and explanations authorized by students in question repositories produced as part of the summative assessment in introductory physics courses over two academic sessions. Mapping question quality onto the levels in the cognitive domain of Bloom's taxonomy, we find that students produce questions of high quality [3].

There are studies that emerged that have assessed the impact on student engagement and learning $[10,19]$ including the summatively assessed component in an introductory physics course $[3]$.

Poor student performance on assessment tasks may not simply stem from a lack of content knowledge [20, 25]. Instead, it is argued that many students possess the requisite formal knowledge and are able to activate it successfully in some situations, but they experience difficulties triggering that same knowledge in certain other contexts.

A basic premise requires students to develop assessment content themselves, in order to challenge them to operate at higher cognitive levels than they might otherwise do in the normal 
course of their studies, encouraging a deeper approach to learning [4]. It established that undergraduate students perform poorly in comparison to experts when they are required to classify physics problems by the physics principles required to solve them [23].

\subsection{Learning Outcomes Measured by the Physics Diagnostic Test as Matched by the Entry Requirement for the BS Astronomy Technology.}

Table 1. Learning Outcomes Measured by the Physics Diagnostic Test

\begin{tabular}{|l|l|l|}
\hline Learning Outcomes & Remarks \\
\hline $\begin{array}{l}\text { 1. Apply the basic mathematical tools } \\
\text { commonly used in solving problems } \\
\text { relating vector analysis. }\end{array}$ & Matched \\
\hline 2. & $\begin{array}{l}\text { Recognize motion as a critically important } \\
\text { in assessing physical laws. }\end{array}$ & Matched \\
\hline 3. $\begin{array}{l}\text { Apply Newton's Laws in the areas of } \\
\text { classical mechanics to expand the } \\
\text { knowledge of the physical universe. }\end{array}$ & Matched \\
\hline 4. $\begin{array}{l}\text { Exercise the use of energy, its forms and } \\
\text { conservation, in any form of } \\
\text { communication that shows theoretical and } \\
\text { experimental concepts in a clear and } \\
\text { concise manner of understanding. }\end{array}$ & Matched \\
\hline
\end{tabular}

Table 1 shows the learning outcomes measured by the physics diagnostic test. The application of the basic mathematical tools commonly used in solving problems relating vector analysis was fully matched in the entry requirement as it was shown in the physics diagnostic test having four questions relating vector analysis. The learning outcomes to recognize motion as a critically important in assessing physical laws, the application of Newton's laws in areas of classical mechanics to expand the knowledge of the physical universe; and the exercise of the use of energy, its forms and conservation, into any form of communication that shows theoretical and experimental concepts in a clear and concise manner of understanding reveals that it also matched the entry requirement for the BS Astronomy Technology students.

These learning outcomes are presented to be in need merely for the forthcoming subjects that requires these basic understanding and knowledge that would cater major subjects in the astronomy department, such as celestial mechanics, advanced physics, thermodynamics, particle physics, astrophysics, and the like. This shows that the learning outcomes measured by the physics diagnostic test are matched by the entry requirement for the BS Astronomy Technology.

The Department of Earth and Space Sciences' entry requirement for the BS Astronomy Technology program is that the students should show their current state of knowledge, conceptual understanding, and expertise to be able to develop further the effective and appropriate plan to obtain new knowledge for scientific goals and to accumulate the pursuit of innovative intellectual interest.

The result of the findings deeply depends upon the magnitude on whether the learner's achievement determines what they are taught and what they can learn and the type of school (public or private) as a teaching environment affects the learning outcomes [21]. Moreover, then it is also shown that instructional practices depend on what teachers bring to the classroom and that professional competence is a crucial factor in classroom and school practices [7, 17] and a contemporary view of teaching also includes professional activities at the school level which have greater impact on student achievement $[8,9,11]$. 


\subsection{Significant difference in the results of the physics diagnostic test in terms of the result of the RTU entrance exam.}

Table 2. Significant Difference in the Physics Diagnostic Test in Terms of Entrance Exam Result

\begin{tabular}{|c|c|c|c|c|c|c|c|}
\hline \multirow{2}{*}{ Group } & \multirow{2}{*}{$\bar{x}$} & \multirow{2}{*}{ df } & \multicolumn{2}{|c|}{ t-value } & \multirow{2}{*}{ P-value } & \multirow{2}{*}{ Decision } & \multirow{2}{*}{ Remarks } \\
\hline & & & Computed & Tabular & & & \\
\hline Average & 68.85 & \multirow[b]{2}{*}{7} & \multirow[b]{2}{*}{0.03842} & \multirow[b]{2}{*}{5.987378} & \multirow[b]{2}{*}{0.851071} & \multirow{2}{*}{$\begin{array}{l}\text { Failed to } \\
\text { Reject Ho }\end{array}$} & \multirow{2}{*}{$\begin{array}{l}\text { Not } \\
\text { Significant }\end{array}$} \\
\hline $\begin{array}{l}\text { Above } \\
\text { Average }\end{array}$ & 67.725 & & & & & & \\
\hline
\end{tabular}

Level of Significance 0.05

Table 2 shows the significant difference in the physics diagnostic test in terms of entrance exam result. The tabular value of 5.987378 is greater than the computed value of $0.03842, \mathrm{t}_{\mathrm{tv}}=$ $5.987378>\mathrm{t}_{\mathrm{cv}}=0.03842$ at $\alpha=0.05$, and that the observed outcome is projected to be as high as $85.1071 \%$ as $p$-value $=0.851071>\alpha=0.05$. With this high probability, statistically, this may not appear very likely, so there is no sufficient evidence to reject the null hypothesis. This indicates that it failed to reject the null hypothesis and therefore conclude that there is no significant difference in the physics diagnostic test in terms of entrance exam result.

This result coincides with the study that the study delivered simultaneous multiple regression had been conducted and showed the combination of mathematical thinking skills that predict students' physics achievement was statistically significant [14]. Physics is a subject which often attracts negative attitudes. Students possess negative attitudes towards the physics laboratory as much as towards physics lesson and physics exams. It is evident that this negative attitude is largely expressed as anxiety [5].

\section{CONCLUSION}

Based on the results and findings, it shows that the physics diagnostic test measures the following learning outcomes: application of the basic mathematical tools commonly used in solving problems relating vector analysis; recognize motion as a critically important in assessing physical laws; application of Newton's Laws in the areas of classical mechanics to expand the knowledge of the physical universe; and to exercise the use of energy, its forms and conservation, into any form of communication that shows theoretical and experimental concepts in a clear and concise manner of understanding. The performance of the incoming freshmen astronomy students in the physics diagnostic test shows that most of the students have very satisfactorily understanding in vectors, motion, Newton's law, and energy as they have the most number of correct answers respectively. The learning outcomes measured by the physics diagnostic test is matched with the entry requirements for the BS Astronomy Technology relating concepts in vectors, motion, Newton's Laws, and energy. The tabular value of 5.987378 is greater than the computed value of $0.03842, \mathrm{t}_{\mathrm{tv}}$ $=5.987378>\mathrm{t}_{\mathrm{cv}}=0.03842$ at $\alpha=0.05$, and that the observed outcome is projected to be as high as $85.1071 \%$ as $p$-value $=0.851071>\alpha=0.05$. With this high probability, statistically, this may not appear very likely, so there is no sufficient evidence to reject the null hypothesis.

It is therefore concluded that the physics diagnostic test match entry requirement for BS Astronomy Technology and that there is no significant difference in the physics diagnostic test between the BS Astronomy Technology college freshman students.

Furthermore, It is probable that in teaching physics, the implications of mathematical concept can be viewed as a simple expression, because it is more important that students fully inculcate the principles and concepts of physics without the complex mathematical expressions. And, in accepting students in the department, it is recommended that in lieu of the verbal description attained by the students in the entrance examination, the department may have a diagnostic test that would fit in their corresponding courses, and do not rely on the result of their mathematics and physics grade from high school as well as the result of the RTU entrance exam. 


\section{References}

[1] K. Antje, et al., Towards a Conceptual Diagnostic Survey in Nuclear Physics, European Journal of Physics, (32) 1 (2011).

[2] Bagno, E., et al., Meeting the Challenge of Students' Understanding of Formulae in Highschool Physics: A Learning Tool. Physics Education. (43) 1 (2008).

[3] Bates, S. P. et al. Student Generated Content: Using PeerWise to Enhance Engagement and Outcomes in Introductory Physics Courses. In 2011, Physics Education Research Conference, AIP Conf. Proc. 1413, 123 (2012).

[4] Bates, S. et al., Assessing the Quality of a Student-Generated Questions Repository, Physics Education Research, (10) 2 (2014).

[5] Berber, N., Developing a Physics Laboratory Anxiety Scale, Asia-Pacific Forum on Science Learning and Teaching. (14) 1. Article 7, p.1 (2013).

[6] Brass, C. et al., Quality Learning of Physics: Conceptions held by High School and University Teachers, Research in Science Education, 33 (2), 245- 271 (2003).

[7] Campbell, A. et al., Practitioner Research and Professional Development in Education, SAGE Publications Limited. (2004).

[8] Darling-Hammond, L., Teacher Quality and Student Achievement: A Review of State Policy Evidence, Education Policy Analysis Archives, 8 (1), 1-15 (2000).

[9] Darling-Hammond, L. et al., Does Teacher Certification Matter? Evaluating the Evidence, Educational Evaluation and Policy Analysis, 23 (1), 57-77 (2001).

[10] Denny, P. et al., PeerWise: Students Sharing their Multiple Choice Questions, In Proceeding of the Fourth International Workshop on Computing Education Research (ACM, New York). 51-58 (2008).

[11] Goldhaber, D., \& Anthony, E., Teacher Quality and Student Achievement, Urban Diversity Series, New York N. Y.: Eric Clearinghouse on Urban Education. (2003).

[12] Guido, R.M. D., Attitudes and Motivation towards Learning Physics. International Journal of Engineering Research and Technology. (2) 11, 2087-2094 (2013).

[13] Hall, N., \& Webb, D., Instructors' Support of Student Autonomy in an Introductory Physics Course, Physic Education Research. (10) 2 (2014).

[14] Jiar, Y. K., \& Long, C. Y., Mathematical Thinking and Physics and Physics Achievement of Secondary School Student, Faculty of Education, Universiti Teknologi Malaysia. (2012).

[15] Kautz, C. H. et al., Student Understanding of the Ideal Gas Law, Part II: A Microscopic Perspective, Am. J. Phys. 73, 1064 (2005).

[16] Kerrison, R., Retraining Chemistry Teachers in the Philippines, Research in Science Education. 22, 248-254 (1992).

[17] Kunter, M., \& Baumert, J., Who is the expert? Construct and Criteria Validity of Student and Teacher Ratings of Instruction, Learning Environments Research, 9 (3), 231-251 (2006).

[18] Kryjevskaia, M. et al., Answer First: Applying the Heuristic-Analytic Theory of Reasoning to Examine Student Intuitive Thinking in the Context of Physics, Physics Education Research. (10) 2 (2014).

[19] Paterson, J., et al., Uses of Peer Assessment in Database Teaching and Learning, in Data Security and Security Data, Lecture Notes in Computer Science, Vol. 6121, edited by L. MacKinnon (Springer, Berlin, Heidelberg) 135-146 (2012). 
[20] Sabella, M., \& Cochran, G. L., Evidence of Intuitive and Formal Knowledge in Student Responses: Examples from the Context of Dynamics, AIP Conf. Proc. 720, 89 (2004).

[21] Scheerens, J., Teachers' Professional Development: Europe in International Comparison, A Secondary Analysis based on the TALIS dataset. The Netherlands: University of Twente. (2009).

[22] Sharma, S., \& Ahluwalia, P. K., Diagnosing Alternative Conceptions of Fermi Energy among Undergraduate Students, European Journal of Physics, (33) 4 (2012).

[23] Singh, C., Student Understanding of Symmetry and Gauss's Law of Electricity, Am. J. Phys. 74, 923 (2006).

[24] Treagust, D., Development and use of Diagnostic Tests to Evaluate Students' Misconceptions in Science, International Journal of Science Education. (10) 2 (2007).

[25] Watkins, E., \& Sabella, M., Examining the Effectiveness of Clickers on Promoting Learning by Tracking the Evolution of Student Responses, AIP Conf. Proc. 1064, 223 (2008).

[26] Wittmann, M., et al., Making Sense of How Students make Sense of Mechanical Waves, Phys. Teach. (1999). 